\title{
Biofortification of Common Bean for Higher Iron Concentration
}

\author{
Stephen Beebe* \\ Alliance Bioversity International and CIAT, Cali, Colombia
}

Common bean (Phaseolus vulgaris L.) is a staple food of smallholder farmers and poor urban consumers in Latin America and eastern-southern Africa among whom iron deficiency is frequent. Bean was domesticated in Mexico and the southern Andes, creating two distinct gene pools. Evaluation of a core collection of 1,441 entries revealed average concentrations of $55 \mathrm{mg} \mathrm{kg}^{-1}$ iron. A breeding target was set at $44 \mathrm{mg} \mathrm{kg}^{-1}$ iron above the level in a local check variety, while $50 \%$ of goal or a $22 \mathrm{mg} \mathrm{kg}^{-1}$ advantage was accepted as "biofortified." In a bioefficacy trial among college-age women in Rwanda, high iron beans improved iron status and enhanced cognitive ability, brain function, and work efficiency. However, breeding progress has been slow, likely due in part to homeostatic mechanisms whereby organisms moderate iron and zinc uptake. This phenomenon may represent resistance to increasing concentration of these elements. Crosses between gene pools may "jumble" genes for homeostasis and permit high levels. A second breeding strategy is the use of sister species that evolved in iron-poor environments and that could be more receptive to iron uptake. Future breeding may also increase attention on improving bioavailability through mechanisms such as non-or-slow darkening grain or low phytate mutants. Changing dietary patterns in developed countries could increase iron deficiency and create demand for iron biofortified beans.

Keywords: homeostasis, breeding, Phaseolus, iron nutrition, bioavailability

\section{INTRODUCTION}

Common bean (Phaseolus vulgaris L.) was domesticated in Mexico and in the southern Andes resulting in two major gene pools, the Mesoamerican and the Andean (Kwak and Gepts, 2009), and with possible incipient domestication in the northern Andes (Islam et al., 2001). Production and consumption of bean are greatest in Latin America, the Caribbean and in East and southern Africa, with specific preferred grain types that condition acceptance in each country or region. Many farms are $<10$ hectares, and some holdings in Africa are less than a hectare. In such situations climbing beans are an important alternative, producing as much as three times the yield per area compared to bush growth habits (Sperling and Muyaneza, 1995). Where land shortages are less acute, most farmers prefer bush beans which require less labor inputs. The smallholder mode of production is often associated with low productivity and acute levels of poverty with accompanying problems of both macronutrient and micronutrient deficiencies.

Focused on micronutrients, HarvestPlus adopted genetic enhancement of iron, zinc, and vitamin A as priorities. Beans emerged as an option for enhancing iron and zinc concentrations. In 1994 the common bean participated in an exploratory initiative to determine the feasibility of breeding for higher micronutrients. After two short term phases to explore 
genetic variability, determine the stability of the trait over environments, and confirm the possibility of transferring the trait through breeding, HarvestPlus (a.k.a. the Biofortification Challenge Program) was launched, later to be incorporated into the Agriculture for Nutrition and Health (A4NH) CGIAR Research Program, with high priority for beans in Africa (Andersson et al., 2017; Mulambu et al., 2017). After a quarter of a century of experience in biofortification of beans, it is timely to reflect on progress, obstacles, learnings, and the way forward.

\section{BIOFORTIFICATION AND PUBLIC HEALTH}

Biofortification was originally conceived as addressing populations with limited access to health services or industrially fortified foods in rural areas, but it is now evident that urban populations also need improved diets. An estimated 1.5-2 billion individuals suffer from iron deficiency (Lynch, 2011). The priority target populations for improved iron nutrition are children, and women in the fertile age. Children in particular cannot consume sufficient volumes of staples to satisfy their requirements, and need nutrient dense foods. While poverty is an important determinant of anemia (Balarajan et al., 2011), data from the World Bank (2020) suggest that economic development does not necessarily assure low levels of anemia. Costa Rica has very low poverty, but its level of anemia in children $(28.7 \%)$ is comparable to that of Honduras (31.4\%), one of the poorest countries in the hemisphere. Rwanda has almost three times as much poverty as South Africa (55 vs. 18.9\%) but the two countries have almost identical prevalence of anemia in children (36.2 vs. $36.8 \%$ ). Even in the United States anemia has risen over a 10 -year period from 4 to $7 \%$, with levels three times higher among ethnic minorities (Hong Le, 2016). These observations suggest that anemia is not readily addressed by economic development alone. Quality of diet must be addressed consciously to assure adequate intake of bioavailable nutrients.

\section{BIOEFFICACY OF BIOFORTIFIED BEANS}

Bioefficacy trials evaluate the value of foods in supplying nutrients to living beings. Trials with biofortified beans in rats (Welch et al., 2000), pigs (Tako et al., 2009), and chicks (Tako et al., 2014) gave positive results, leading to the establishment of trials with humans. A study with high iron beans (HIB) and normal beans was carried out with young women in Rwanda, most of whom were iron deficient or anemic. After four and a half months the high iron bean group showed a statistically greater increase in hemoglobin $(3.8 \mathrm{~g} / \mathrm{L}), \log$ serum ferritin $(0.1$ $\log \mu \mathrm{gr} / \mathrm{L})$ and total body iron $\left(0.5 \mathrm{mg} \mathrm{kg}^{-1}\right)$ (Haas et al., 2016), superior cognitive ability (Murray-Kolb et al., 2017), increased neuron activity (Wenger et al., 2019), and superior work capacity (Luna et al., 2020). In a trial involving Mexican school children age $6-10$, the effect of high iron beans on transferrin receptor was narrowly not significant ( $p=0.054$ ) (Finkelstein et al., 2019). However, among the $25 \%$ of children that were most deficient, high iron beans resulted in lower transferrin receptor and a significant reduction in deficiency (Haas et al., 2011). Additional studies among other populations with different dietary patterns and combinations of foods would be preferable.

\section{BREEDING FOR HIGHER IRON}

Although increased concentrations of both iron and zinc are breeding objectives, most effort has been devoted to iron which has responded more rapidly to selection. As the first step in developing a breeding program, a core collection was evaluated to assess the genetic diversity of iron and zinc concentrations (Tohme et al., 1995). Among 1,441 entries evaluated by Inductively Coupled Plasma Spectrometry (ICP), samples presented an average of $55 \mathrm{mg} \mathrm{kg}^{-1}$ iron, and $28 \mathrm{mg}$ $\mathrm{kg}^{-1}$ zinc, with extremes of $102 \mathrm{mg} \mathrm{kg}^{-1}$ and $54 \mathrm{mg} \mathrm{kg}^{-1}$, respectively, while G10022 was identified within a core collection of wild Phaseolus vulgaris (Beebe et al., 2000). In the same period a core collection with 150 accessions of sister species $P$. coccineus and $P$. dumosus was created. One $P$. dumosus accession, G35575 presented iron levels well above $100 \mathrm{mg} \mathrm{kg}^{-1}$, and was incorporated into the breeding program.

Consultations with nutritionists established a breeding goal level of $44 \mathrm{mg} \mathrm{kg}^{-1}$ iron above the value of a standard local variety (assumed to be $\sim 50 \mathrm{mg} \mathrm{kg}^{-1}$ ) to achieve $30 \%$ of average daily iron requirement, assuming 7\% bioavailability, $90 \%$ retention after cooking, and a high level of consumption of 200 grams per day for adults and 100 grams per day for children (Andersson et al., 2017). Since breeding goals are not met in the short term, an intermediate goal of $50 \%$ or $22 \mathrm{mg} \mathrm{kg}^{-1}$ over a local check variety was accepted as "biofortified."

In a QTL study of mineral concentration, Blair et al. (2009) found four linkage groups associated with iron and four with zinc, with a QTL cluster on B11 (now Pv11). Later, a metaQTL analysis summarized results of seven different populations, identifying 12 meta-QTL on eight chromosomes, of which eight meta-QTL were associated with both iron and zinc (Izquierdo et al., 2018). A diallel study of six parental materials revealed both additive and non-additive inheritance, with narrow sense heritabilities of $71 \%$ for iron, $83 \%$ for zinc, and a correlation of $r$ $=0.75$ between the two elements (Mukamuhirwa et al., 2015).

To be adopted by farmers, HIB must perform agronomically as well as standard varieties, but combining multiple quantitative traits of high iron and acceptable yield in grain types of the desired color, size, and shape was a challenge. High iron was associated with poor yield potential, and with a reduced seed sink (fewer pods, fewer seeds per pod, or poorly filled seed), leading to concentration of iron in a smaller seed mass. Once these limitations were recognized, selection focused on lines with well filled pods and high iron. While iron levels may vary over environments, ranking of genotypes is normally very similar.

High iron varieties have been released in at least 10 countries in Africa and Latin America (Table 1). High iron was first attained in climbing beans that were released as varieties in Rwanda, Uganda and the Democratic Republic of Congo, and later Colombia. These are represented by lines such as NUV 119 and BIO 102. In the Mesoamerican gene pool, breeding objectives have sought to combine high iron with tolerance to drought 
TABLE 1 | Some high iron bean varieties in different countries and diversity of parental sources of the high iron trait in development of varieties ${ }^{a}$.

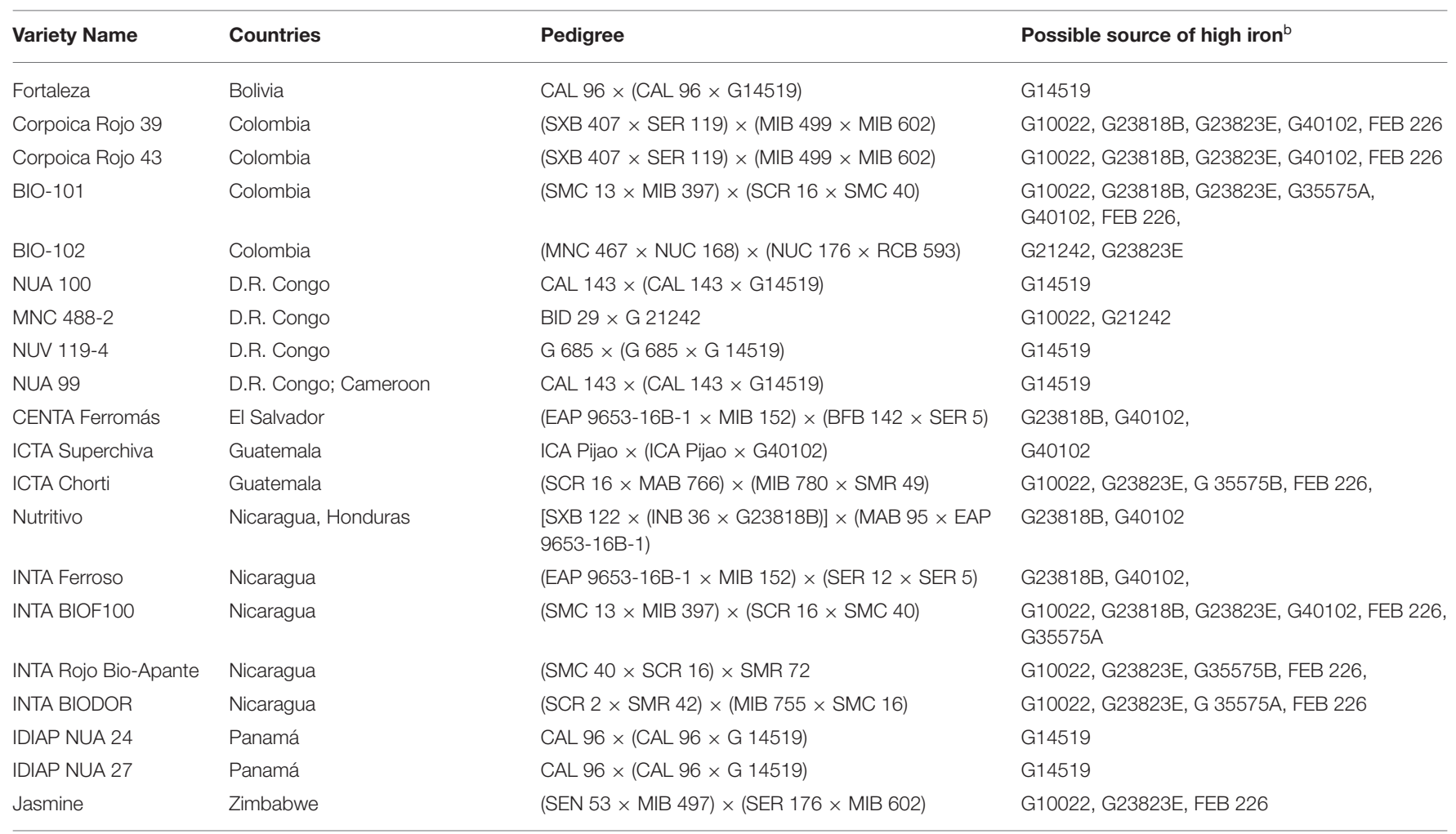

${ }^{a}$ Cited with permission of HarvestPlus.

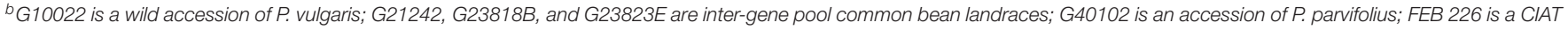
common bean breeding line. G35575A and B are accessions of $P$. dumosus.

and/or resistance to virus (BGYMV in Central America, BCMNV in East Africa). Biofortified bush beans of the Mesoamerican gene pool have been released for use in Colombia, Guatemala, Nicaragua, El Salvador, and Honduras. Most HIB are used for home consumption, but in Rwanda a modest market is developing for high iron precooked beans, and in Burundi a composite flour including HIB is being produced. In Nicaragua $\mathrm{HIB}$ are being channeled into school feeding programs.

\section{BIOLOGY OF IRON IN BEANS}

Reflections on the biology of iron in plants may reveal characteristics of mechanisms for higher levels. Iron is a heavy metal and can be toxic in high concentrations. Therefore, its uptake is regulated by mechanisms of homeostasis that maintain its concentration within biologically acceptable limits (Morrissey and Guerinot, 2009). Iron homeostasis has been studied intensively in plants (Connorton et al., 2017) and comparable mechanisms exist for zinc (Sinclair and Krämer, 2012). Homeostasis may have important implications for biofortification if efforts to increase concentration in grains confront resistance to substantial changes from homeostasis.

A possible case of homeostasis limiting iron uptake was observed in the bush forage legume Cratylia argentea that evolved in an acid, iron-rich soil in Brazil (Argel and Lascano, 1998), and that appears to protect itself against excess iron. When cultivated in an alkaline, iron-poor soil in CIAT, Colombia it suffers iron chlorosis, supposedly due to self-imposed restriction of iron uptake acquired through evolution. On the other hand, disruption of homeostasis in a mutant of garden pea (Pisum sativum) led to toxicity through excess iron absorption (Kneen et al., 1990). These examples illustrate homeostasis, both in its tight regulation in Cratylia, or its disruption in Pisum. To successfully increase concentration of minerals in grain, it will be necessary to modify homeostatic mechanisms (though much more modestly than in the example in Pisum).

Such disruption of homeostasis may explain the results with several high iron gene bank accessions in the core collection cited above (Beebe et al., 2000). DNA analysis demonstrated that accessions G21242, G23818, and G23823 that were employed as sources in the breeding program were the result of intergene pool hybridizations (Islam et al., 2004). Furthermore, QTL analysis of a Mesoamerican-Andean inter-gene pool cross revealed different alleles for seed iron concentration and for iron reductase which is a key mechanism for iron acquisition (Blair et al., 2010). If the two gene pools have evolved some distinct genes for homeostatic mechanisms, hybridization and segregation could have rearranged these genes and disrupted homeostasis, creating genetic variability and the potential for genetic improvement.

On the other hand, the experience cited with Cratylia suggests that the species evolution is a factor in determining receptiveness 
TABLE 2 | Iron values $\left(\mathrm{mg} \mathrm{kg}^{-1}\right)$ of interspecific lines of bush growth habit derived from the cross [(INB $834 \times$ G 40264) F1 × INB 841] F1 × SMR 139 as measured by XRF technology.

\begin{tabular}{lcc}
\hline & Iron & Zinc \\
\hline VAP 5 & 100.3 & 42.0 \\
VAP 11 & 93.3 & 37.7 \\
VAP 10 & 93.0 & 41.3 \\
VAP 6 & 90.0 & 34.3 \\
VAP 9 & 88.0 & 37.7 \\
VAP 8 & 86.7 & 37.0 \\
VAP 7 & 86.0 & 34.3 \\
VAP 4 & 82.3 & 31.7 \\
SMC 33* & 78.0 & 32.0 \\
DOR 500** & 48.7 & 24.3 \\
CAL 96 & $4 * *$ & 21.0 \\
L.S.D. (0.05) & 12.1 & 4.9 \\
\hline
\end{tabular}

INB lines are interspecific progenies of common bean and P. acutifolius; G40264 is an accession of P. parvifolius; SMR 139 is a common bean high iron breeding line.

*High mineral check line; ${ }^{* \star}$ low mineral Mesoamerican check line; ${ }^{* \star *}$ low mineral Andean check line.

to iron uptake. Just as evolution in an iron-rich acid soil may lead to reduced receptivity to iron, evolution in an iron-poor alkaline soil might lead to homeostatic mechanisms with greater receptivity to iron. For example, $P$. acutifolius and its sister species $P$. parvifolius evolved in alkaline soils (Freytag and Debouck, 2002) and were crossed to common bean (Barrera et al., 2018). Interspecific progeny and checks were evaluated over seasons in CIAT's experiment station in Cali, Colombia (average annual temperature $26^{\circ} \mathrm{C}$; mollisol soil; $\mathrm{pH} 7.8$ ) with standard agronomic management of pest and disease controls. Mineral concentrations were evaluated with X-ray Flourescence (XRF) technology (Guild et al., 2017). Lines presented more than $15 \mathrm{mg} \mathrm{kg}^{-1}$ iron above the high mineral check, and $10 \mathrm{mg} \mathrm{kg}^{-1}$ zinc higher than the check (Table 2). This illustrates how an appreciation of the evolution of a species over millennia can reveal its potential to contribute useful alleles.

Examining the pedigrees of biofortified bean varieties reveals the diversity of sources employed for high iron genes (Table 1). Common bean landraces combining Andean and Mesoamerican genes have been the backbone of the program, while wild bean G10022 and P. dumosus accession G35575 also appear in many pedigrees. "ICTA Superchiva" from Guatemala deserves special attention, since its only source of high iron is $P$. parvifolius. This tends to validate the hypothesis that species that evolved in dry alkaline soil environments can contribute high iron genes. Furthermore, the $P$. parvifolius accession in "Superchiva" is not the same accession that is in the pedigree of the high iron lines in Table 2, again suggesting that high iron is a trait associated with the species.

\section{FRONTIERS IN BIOAVAILABILITY}

Enhancement of iron bioavailability could broaden the scope for impact from biofortified beans to regions of intermediate levels of consumption, but to date no varieties have been created with improved bioavailability per se. Breeders need simple and rapid phenotyping methods to adapt selection to broad based varietal development programs. Recent findings offer hope for such selection tools for bioavailability based on traits of multiple utility.

One such promising trait is the slow darkening (SD) characteristic of the seed coat, and its related trait, seed nondarkening (ND). A comparison of SD and normal pinto beans suggested as much as a 4 -fold increase in iron bioavailability with slow darkening (Glahn et al., 2019). SD also improves market value because consumers associate darkened grain with grain aging, seed hardness and slow cooking. SD is controlled by a single recessive gene $s d$, while ND results from the recessive $j$ gene (Elsadr et al., 2011). An SSR marker is closely associated with the SD allele (Felicetti et al., 2012). Seed darkening can be phenotyped by observation over time, or by exposing grain to sunlight or to ultra-violet light for a few hours. It can also be selected through marker assisted selection (Felicetti et al., 2012). Thus, simple systems exist for selection of the SD or ND traits that will simultaneously improve bioavailability. Some yellow beans also present high iron bioavailability in the Caco 2 test (Wiesinger et al., 2018), and in an in vivo chick model (Wiesinger et al., 2019). Yellow beans accumulate kaempferol 3-glucoside in their seed coats which was identified as an uptake promoter.

Shorter cooking time is highly desirable and has also been associated with superior iron bioavailability. A study of 12 cultivars revealed a negative correlation between longer cooking time and iron bioavailability in the Caco2 test $(r=-0.537)$ (Wiesinger et al., 2016). Another approach to improve bioavailability is to remove phytate and so to eliminate one of the major anti-nutrients in the grain. Campion et al. (2009) reported a promising mutant of common bean that presented a $90 \%$ reduction in phytate in grain. The low phytate method was approached with caution and is still under evaluation as a breeding strategy. In other crops low phytate has carried a yield penalty but in beans this has not been detected in environments where it has been tested (unpublished data).

\section{BIOFORTIFICATION FOR ZINC IN BEANS}

Although zinc was adopted as a breeding objective for beans, and Donangelo et al. (2003) demonstrated a positive effect of high zinc beans in a human trial using zinc isotopes, response to selection has been slower than that for iron. The goal level for zinc biofortification is $17 \mathrm{mg} \mathrm{kg}^{-1}$ above local materials, such that $50 \%$ of goal or $8.5 \mathrm{mg} \mathrm{kg}^{-1}$ could be considered as biofortified. Data presented in Table 2 are representative of experience until recently. High mineral check SMC 33 presents $32 \mathrm{mg} \mathrm{kg}^{-1}$, while standard black seeded variety DOR 500 presents $24 \mathrm{mg} \mathrm{kg}^{-1}$, such that the best materials can just scarcely be considered biofortified.

Two recent developments may raise attention to biofortification for zinc in beans. First, nutritionists recently highlighted zinc as even more important than iron in East Africa (IFNA, 2018). Secondly, recent data mentioned above and cited 
in Table 2 with interspecific crosses with Phaseolus parvifolius offer promise of a more significant gain in zinc concentration. These results suggest that wider attention to zinc is merited.

\section{DISCUSSION}

While bioefficacy results are positive, they also present a conundrum. Bioefficacy trials have been executed in populations with high levels of consumption, but many other populations consume beans at a lower level and are also iron deficient. Novel breeding strategies are needed to create bean varieties that impact significantly on iron nutrition with more moderate levels of consumption.

In retrospect, more attention to the biology of iron in bean could have accelerated genetic gain in iron levels, through an appreciation of homeostatic mechanisms and their evolution, and earlier understanding of the factors affecting iron concentration. On the other hand, knowledge of bioavailability factors bodes well for future progress. Several traits offer options to address bioavailability more systematically in breeding programs, either through phenotyping or through marker assisted selection. The emerging nutritional benefits of these traits present a win-win scenario. As broader understanding leads to higher levels and/or better absorption of bean iron, more consumers with intermediate levels of consumption may benefit from biofortified beans.

Accumulated knowledge on the genetics of high iron can also speed progress. Meta-QTL analysis showing oligogenic control could be exploited through conventional marker assisted selection, or genomic selection might be employed. Gene editing could block the production of antinutrient fractions. Genome sequencing would reveal reliable molecular markers for known genes such as the recessive $j$ gene. A more speculative approach could be to activate genes for leghemoglobin in the seed. Heme iron is highly bioavailable and legumes express genes for hemoglobin in nodules. Is leghemoglobin iron bioavailable? If so, can leghemoglobin genes be expressed in seed through genetic engineering? Such options highlight a need for a better knowledge of basic genetics.

The original focus of HarvestPlus has been poor populations in Africa and in Latin America with limited access to health services and industrially fortified foods. In the future other tendencies may create new demand for biofortified crops.

\section{REFERENCES}

Andersson, M. S., Saltzman, A., Virk, P. S., and Pfeiffer, W. H. (2017). Progress update: crop development of biofortified staple food crops under HarvestPlus. Afr. J. Food Agric. Nutr. Dev. 17, 11905-11935. doi: 10.18697/ajfand.78.HarvestPlus05

Argel, P., and Lascano, C. E. (1998). Cratylia argentea (Desvaux) O. Kuntz: Una Nueva Leguminosa Arbustiva Para Suelos Ácidos en Zonas Subhumidas Tropicales. Cali, Colombia: Centro Internacional de Agricultura Tropical (CIAT), 7. (Gramineas y leguminosas tropicales; Proyecto IP-5, Circular Año 2, no. 2.)

Balarajan, Y., Ramakrishnan, U., Ozaltin, E., Shankar, A. H., and Subramanian, S. V. (2011). Anaemia in low-income and middle-income countries. Lancet 378, 2123-2135. doi: 10.1016/S0140-6736(10)62304-5
Currently the ecological movement highlights the need for reduced meat consumption. Will a move toward plant protein and reduced meat consumption create a dietary iron gap and make HIB more relevant? Another tendency is toward low carbohydrate diets and less processed foods. Will low carb, more "natural" diets reduce consumption of industrially fortified wheat flour and increase iron deficiency? Addressing such possible needs could require informing the public about the advantages of HIB.

Crop plant breeders work on a time horizon of $8-10$ years from the making of crosses, to the point of seeing populations consuming their products widely. On this time scale, one can still expect biofortified beans to have a significant role for the rural and urban poor in the 2030's. On the medium to long term, bean breeders will want to consider if other populations will be an audience for their products, and what form those products may take.

\section{DATA AVAILABILITY STATEMENT}

The original contributions presented in the study are included in the article, further inquiries can be directed to the corresponding author/s.

\section{AUTHOR CONTRIBUTIONS}

The author confirms being the sole contributor of this work and has approved it for publication.

\section{FUNDING}

Financial support from DANIDA, the Bill and Melinda Gates Foundation and the Department for International Development (UK) through HarvestPlus, the United States Agency for International Development, and the Canadian International Development Agency is gratefully acknowledged.

\section{ACKNOWLEDGMENTS}

The author wishes to express gratitude to scientists in the National Research Programs who have carried results of this research to farmers and consumers. 
Campion, B., Sparvoli, F., Doria, E., Tagliabue, G., Galasso, I., Fileppi, M., et al. (2009). Isolation and characterisation of an lpa (low phytic acid) mutant in common bean (Phaseolus vulgaris L.). Theor. Appl. Genet. 118, 1211-1221. doi: 10.1007/s00122-009-0975-8

Connorton, J. M., Balk, J., and Rodríguez-Celma, J. (2017). Iron homeostasis in plants - a brief overview. Metallomics 9, 813-823. doi: 10.1039/C7MT00136C

Donangelo, C. M., Woodhouse, L. R., King, S. M., Toffolo, G., Shames, D. M., Viteri, F. E., et al. (2003). Iron and zinc absorption from two bean (Phaseolus vulgaris L.) genotypes in young women. J. Agric. Food Chem. 51, 5137-5143. doi: $10.1021 /$ jf030151w

Elsadr, H. T., Wright, L. C., Pauls, K. P., and Bett, K. E. (2011). Characterization of seed coat post harvest darkening in common bean (Phaseolus vulgaris L.). Theor. Appl. Genet. 123, 1467-1472. doi: 10.1007/s00122-011-1683-8

Felicetti, E., Song, Q., Jia, G., Cregan, P., Bett, K. E., and Miklas, P. N. (2012). Simple sequence repeats linked with slow darkening trait in pinto bean discovered by single nucleotide polymorphism assay and whole genome sequencing. Crop Sci. 52, 1600-1608. doi: 10.2135/cropsci2011.12.0655

Finkelstein, J. L., Mehta, S., Villalpando, S., Mundo-Rosas, V., Luna, S., Rahn, M., et al. (2019). A randomized feeding trial of iron-biofortified beans in school children in Mexico. Nutrients 11:381. doi: 10.3390/nu11020381

Freytag, G. F., and Debouck, D. G. (2002). Taxonomy, distribution, and ecology of the genus Phaseolus (Leguminosae-Papilionoideae) in North America, Mexico and Central America. SIDA Bot. Misc. 23, 1-300.

Glahn, R. P., Wiesinger, J. A., and Osorno, J. M. (2019). "Slow darkening pinto beans exhibit enhanced iron bioavailability across multiple production environments in North Dakota," in Abstract Retrieved From the Program of 2019 Meeting of the Bean Improvement Cooperative, 51.

Guild, G. E., Paltridge, N. G., Andersson, M. S., and Stangoulis, C. R. (2017). An energy-dispersive X-ray fluorescence method for analyzing $\mathrm{Fe}$ and $\mathrm{Zn}$ in common bean, maize and cowpea biofortification programs. Plant Soil 419, 457-466. doi: 10.1007/s11104-017-3352-4

Haas, J. D., Luna, S. V., Lung'aho, M. G., Wenger, M. J., Murray-Kolb, L. E., Beebe, S., et al. (2016). Consuming iron biofortified beans increases iron status in Rwandan women after 128 days in a randomized controlled feeding trial. J. Nutr. 146, 1586-1592. doi: 10.3945/jn.115.224741

Haas, J. D., Villalpando, S., Beebe, S., Glahn, R., Shamah, T., and Boy, E. (2011). The effect of consuming biofortified beans on the iron status of Mexican school children. FASEB J. 25. doi: 10.1096/fasebj.25.1_supplement.96.6

Hong Le, C. H. (2016). The prevalence of anemia and moderate-severe anemia in the US population (NHANES 2003-2012). PLoS ONE 11:e166635. doi: 10.1371 /journal.pone.0166635

IFNA (2018). "The initiative for food and nutrition security in Africa," in The ICSA Consultative Workshop in Senegal, 25th-27th April 2018. (Dakar).

Islam, F. M. A., Basford, K. E., Redden, R. J., Gonzalez, A. V., Kroonenberg, P. M., and Beebe, S. (2001). Genetic variability in cultivated common bean beyond the two major gene pools. Genet. Resour. Crop Evol. 49, 271-283. doi: 10.1023/A:1015567513005

Islam, F. M. A., Beebe, S., Muñoz, M., Tohme, J., Redden, R. J., and Basford, K. E. (2004). Using molecular markers to assess the effect of introgression on quantitative attributes of common bean in the Andean gene pool. Theor. Appl. Genet. 108, 243-252. doi: 10.1007/s00122-003-1437-3

Izquierdo, P., Astudillo, C., Blair, M. W., Iqbal, A. M., Raatz, B., and Cichy, K. A. (2018). Meta-QTL analysis of seed iron and zinc concentration and content in common bean (Phaseolus vulgaris L.). Theor. Appl. Genet. 131, 1645-1658. doi: 10.1007/s00122-018-3104-8

Kneen, B. E., LaRue, T. A., Welch, R., and Weeden, N. (1990). Pleiotropic effects of brz: a mutation in Pisum sativum (L.) cv 'sparkle' conditioning decreased modulation and increased iron uptake and leaf necrosis. Plant Physiol. 93, 717-722. doi: 10.1104/pp.93.2.717

Kwak, M., and Gepts, P. (2009). Structure of genetic diversity in the two major gene pools of common bean (Phaseolus vulgaris L., Fabaceae). Theor. Appl. Genet. 118, 979-992. doi: 10.1007/s00122-008-0955-4

Luna, S. V., Pompano, L. M., Lung'aho, M., Gahutu, J. B., and Haas, J. D. (2020). Increased iron status during a feeding trial of iron-biofortified beans increases physical work efficiency in Rwandan women. J. Nutr. 150, 1093-1099. doi: $10.1093 /$ jn/nxaa016
Lynch, S. R. (2011). Why nutritional iron deficiency persists as a worldwide problem. J. Nutr. 141, 763S-768S. doi: 10.3945/jn.110.130609

Morrissey, J., and Guerinot, M. L. (2009). Iron uptake and transport in plants: the good, the bad, and the Ionome. Chem. Rev. 109, 4553-4567. doi: $10.1021 / \mathrm{cr} 900112 \mathrm{r}$

Mukamuhirwa, F., Tusiime, G., and Mukankusi, M. C. (2015). Inheritance of high iron and zinc content in selected bean varieties. Euphytica 205, 349-360. doi: 10.1007/s10681-015-1385-4

Mulambu, J., Andersson, M., Palenberg, M., Pfeiffer, W., Saltzman, A. Birol, E., et al. (2017). Iron beans in Rwanda: crop development and delivery experience. Afr. J. Food Agric. Nutr. Dev. 17, 12026-12050. doi: 10.18697/ajfand.78.HarvestPlus10

Murray-Kolb, L. E., Wenger, M. J., Scott, S. P., Rhoten, S. E., Lung'aho, M. G., and Haas, J. D. (2017). Consumption of iron-biofortified beans positively affects cognitive performance in 18- to 27-year-old Rwandan female college students in an 18-week randomized controlled efficacy trial. J. Nutr. 147, 2109-2117. doi: $10.3945 /$ jn. 117.255356

Sinclair, S. A., and Krämer, U. (2012). The zinc homeostasis network of land plants. Biochim. Biophys. Acta 1823, 1553-1567. doi: 10.1016/j.bbamcr.2012.05.016

Sperling, L., and Muyaneza, S. (1995). Intensifying production among smallholder farmers: the impact of improved climbing beans in Rwanda. Afr. Crop Sci. J. 3, 117-125.

Tako, E., Beebe, S. E., Reed, S., Hart, J. J., and Glahn, R. P. (2014). Polyphenolic compounds appear to limit the nutritional benefit of biofortified higher iron black bean. Nutr. J. 13:28. doi: 10.1186/1475-2891-13-28

Tako, E., Moises Laparra, J., Glahn, R. P., Welch, R. M., Lei, X. G., Beebe, S., et al. (2009). Biofortified black beans in a maize and bean diet provide more bioavailable iron to piglets than standard black beans (Phaseolus vulgaris L.). J. Nutr. 139, 1-5. doi: 10.3945/jn.108.098657

Tohme, J., Jones, P., Beebe, S., and Iwanaga, M. (1995). "The combined use of agroecological and characterisation data to establish the CIAT Phaseolus vulgaris core collection," in Core Collections of Plant Genetic Resources, eds T. Hodgkin, A. H. D. Brown, T. J. L. van Hintum, and C. Spillane (Chichester: Morales John Wiley and Sons), 95-107.

Welch, R. M., House, W. A., Beebe, S., and Cheng, Z. (2000). Genetic selection for enhanced bioavailable levels of iron in bean (Phaseolus vulgaris L.) seeds. J. Agric. Food Chem. 48, 3576-3580. doi: 10.1021/jf0000981

Wenger, M. J., Rhoten, S. E., Murray-Kolb, L. E., Scott, S. P., Boy, E., Gahutu, J. B., et al. (2019). Changes in iron status are related to changes in brain activity and behavior in Rwandan female university students: results from a randomized controlled efficacy trial involving iron-biofortified beans. J. Nutr. 149, 687-697. doi: $10.1093 / \mathrm{jn} / \mathrm{nxy} 265$

Wiesinger, J. A., Cichy, K. A., Glahn, R. P., Grusak, M. A., Brick, M. A., Thompson, H. J., et al. (2016). Demonstrating a nutritional advantage to the fast-cooking dry bean (Phaseolus vulgaris L.). J. Agric. Food Chem. 64, 8592-8603. doi: 10.1021/acs.jafc.6b03100

Wiesinger, J. A., Cichy, K. A., Tako, E., and Glahn, R. P. (2018). The fast cooking and enhanced iron bioavailability properties of the Manteca yellow bean (Phaseolus vulgaris L.). Nutrients 10:1609. doi: 10.3390/nu10111609

Wiesinger, J. A., Glahn, R. P., Cichy, K. A., Kolba, N., Hart, J. J., and Tako, E. (2019). An in vivo (Gallus gallus) feeding trial demonstrating the enhanced iron bioavailability properties of the fast cooking Manteca yellow bean (Phaseolus vulgaris L.). Nutrients 11:1768. doi: 10.3390/nu11081768

World Bank (2020). Available online at: database.worldbank.org/source/worlddevelopment-indicators (accessed June 16, 2020).

Conflict of Interest: The author declares that the research was conducted in the absence of any commercial or financial relationships that could be construed as a potential conflict of interest.

Copyright (c) 2020 Beebe. This is an open-access article distributed under the terms of the Creative Commons Attribution License (CC BY). The use, distribution or reproduction in other forums is permitted, provided the original author(s) and the copyright owner(s) are credited and that the original publication in this journal is cited, in accordance with accepted academic practice. No use, distribution or reproduction is permitted which does not comply with these terms. 